\title{
Efficacy of sorghum peanut blend and corn soy blend plus in the treatment of moderate acute malnutrition in children aged 6-59 months in Karamoja, Uganda: a cluster randomized trial
}

\author{
This article was published in the following Dove Press journal: \\ Nutrition and Dietary Supplements \\ 13 August 2014 \\ Number of times this article has been viewed
}

\author{
Andrew Kiri Amegovu' \\ Sophie Ochola' \\ Patrick Ogwok ${ }^{2}$ \\ Peter Yiga ${ }^{2}$ \\ Juliet Musalima² \\ Mandha Juliana ${ }^{2}$ \\ 'Department of Food, Nutrition \\ and Dietetics, Kenyatta University, \\ Nairobi, Kenya; ${ }^{2}$ Department of \\ Food Technology, Kyambogo \\ University, Kampala, Uganda
}

\begin{abstract}
More than half of the world's deaths in children below 5 years of age are caused by under nutrition. Early management of moderate acute malnutrition (MAM) is necessary to avoid deterioration to severe acute malnutrition. Corn soy blend plus (CSB+) mixed with vegetable oil and sugar is the traditional treatment for MAM but is too expensive for poor countries. The effectiveness of affordable and available local food materials are currently being studied as alternative food supplements to treat malnutrition. In this trial, the efficacy of sorghum peanut blend (SPB) mixed with ghee and honey for the treatment of MAM was compared to that of CSB+ among children 6-59 months old in Karamoja, Uganda. This was a single-blind randomized parallel trial in which two health centers were assigned on a 1:1 ratio to the two study groups. The participants (mothers and their moderately malnourished children) were recruited at the health centers and assigned to the groups depending on the health facility attended. Each child received a daily ration of either $\mathrm{CSB}+$ or SPB for a maximum period of 3 months. Anthropometric measurements of the children were taken on a bi-weekly basis. The primary outcomes were the recovery rate and duration on the program before recovery. Of the recruited 440 participants, 392 completed the study and were included in the analysis (SPB group 194; CSB+ group 198). Analysis was by intention to treat. The recovery rates were not significantly different for the SPB group and the $\mathrm{CSB}+$ group $(82.3 \%$ and $76.8 \%$, respectively; chi-square test $P=0.093$ ). Duration of recovery was significantly shorter for the SPB+ group, with a median of 43 days compared to 57 days for the SPB group (Kaplan-Meier survival test). The recovery rate and the duration of stay in the program were all within the acceptable Sphere Standards ( $\geq 75 \%$ and $\leq 90$ days, respectively). SPB has the potential to treat MAM.
\end{abstract}

Keywords: rehabilitation, Uganda, randomized trial, corn soy blend plus (CSB+), acute malnutrition

\section{Introduction}

Malnutrition levels among children stand at approximately $10 \%$ globally. ${ }^{1}$ About 7.5 million deaths of children $<5$ years are recorded annually in developing countries, and $35 \%$ of these are directly associated with under nutrition. ${ }^{1}$ Moderate acute malnutrition (MAM) defined by weight-for-height $z$ score (WHZ) $<-2$ to $\geq-3$ without edema, affects approximately $11 \%$ of children worldwide. ${ }^{1}$ A child with MAM is at three times greater risk of mortality and morbidity from infectious diseases than their normal counterparts. ${ }^{2}$ MAM causes low appetite, malabsorption of nutrients, and an increased nutritional requirement in children. Consequently, this lowers the immunity
Correspondence: Andrew Kiri Amegovu PO Box 830, Entebbe, Uganda Tel +256772438219

Email kiri_andrew@yahoo.com 
of the child, leading to opportunist diseases and even death due to the severity of the diseases. About $14.6 \%$ of deaths in affected children under 5 years old are due to wasting. Of these deaths, moderate wasting contributes about $10.2 \%$ while severe wasting accounts for $4.4 \% .{ }^{1}$ Studies have shown that children previously suffering from MAM remain at risk of malnutrition and death in the year following recovery. ${ }^{3}$

A child with MAM is normally treated with fortified blended flours, specifically corn soy blend plus (CSB+) or recently with corn soy blend "plus plus" CSB++. ${ }^{4}$ These food supplements are effective in treating MAM but are short-term rather than sustainable intervention for management of recurrent malnutrition in poverty stricken countries. In Uganda, malnutrition is highly prevalent, with over 2 million children below the age of 5 years estimated to be underweight. ${ }^{5}$ It is reported that up to $60 \%$ of child mortality in Uganda is directly linked to malnutrition. ${ }^{6}$ At household level, optimal utilization of locally accessible nutrient-dense foods is demonstrated to be effective in dietary management of MAM. ${ }^{7}$ The foods are familiar, easy to formulate, and cheap, yet provide approximately all the nutrients required. To ensure timely treatment of moderate malnutrition and sustainable supply of food supplements in communities, locally formulated food supplements from locally available foodstuffs need to be explored. In this randomized parallel trial we assessed the effectiveness of sorghum peanut blend (SPB) mixed with cow's ghee and honey, with $\mathrm{CSB}+$ as a comparator, in the treatment of MAM.

\section{Subjects and methods Subjects and setting}

The study participants were children aged 6-59 months with MAM (WHZ $\geq-3$ to $<-2$ without bipedal edema) as well as their mothers/caregivers. The study was conducted at two health centers: Kakamongole and Namalu in Nakapiripirit district, Karamoja region of Uganda. Inhabitants of the area are predominately nomadic pastoralists. Food insecurity levels are high, translating into high malnutrition rates. The staple crops in this region are sorghum and peanut. Cow's ghee and honey are accessible to the population owing to livestock and bee keeping.

\section{Study design}

This was a single-blind cluster randomized parallel study that assessed the efficacy of SPB (the experiment), against CSB+ (a comparator) in treating MAM for a period of $\leq 90$ days as per the Sphere Standards (2004). ${ }^{8}$
The study was conducted from November 2012 to January 2013. Ethical approval was obtained from the Ethical Committee of Uganda National Council of Science and Technology; Reference HS 1188, July 5, 2012, and permission to conduct the study was granted by the Ministry of Health and the Director of Health Services of Nakapiripirit district, Uganda.

\section{Sample size calculation}

The required sample size was 172 per study group. ${ }^{9}$ This was calculated based on $80 \%$ power of the test; $20 \%$ difference in cure by SPB over CSB+, and 5\% level of significance. The calculated sample size was inflated by $30 \%$ to cater for attrition. The final sample size was 220 per study group.

\section{Randomization}

Two health centers, 12 kilometers apart, were randomly assigned on a 1:1 ratio to the two study groups: SPB and $\mathrm{CSB}+$. The randomization was computer-generated using the Microsoft $^{\circledR}$ Excel 2003 software package. Randomization was conducted by a biostatistician who was not part of the research team, so as not to introduce bias. Health centers rather than individual children and their mothers/ caregivers were randomized to the study groups to prevent cross-contamination of the study intervention by sharing of food supplements if close neighbors were assigned to the same study groups. A child and the mother/caretaker were assigned to the study groups based on the proximity of their residence to the health center. The principal investigator was assisted by research assistants (RAs) to conduct the recruitment.

\section{Blinding design}

This was a single-blind study. Only the investigator was aware of the treatment (the nature of the food supplement) given to the experimental group. The hypothesis of the study was concealed from the participants, staff at the health centers, and the RAs who distributed the food and administered the questionnaires.

\section{Selection and training of RAs}

Eight RAs with experience in community work and treatment of acute malnutrition were trained by the principal investigator for 7 days. The role of the RAs was to distribute and give demonstrations on the cooking of the supplementary foods given to the children. The RAs also took anthropometric measurements of the 
children and gave nutrition education to the mothers/ caregivers.

\section{Recruitment of study participants}

The study participants were recruited at the health facilities. Children were first screened at the community level by the VHTs, and those with a mid-upper arm circumference (MUAC) measurement between 11.5-12.5 cm were invited to an enrollment session at the health facilities. At the health facilities, the children were further screened for eligibility $(<-2$ WHZ) and those who qualified were recruited to the study. At this session, the mothers/caregivers were given detailed information about the study without revealing the study hypothesis. The mothers/caregivers were informed of the purpose of the study, potential benefits, and the fact that the study posed no direct or indirect harm to them. The participants were recruited upon their informed consent given by signature or thumb print. The inclusion criteria were mothers/ caregivers: i) willing to participate in the study, and ii) planning to reside in the district for at least 4 months from the time of recruitment to the study. The exclusion criteria included those: i) involved in other research trials, ii) with chronic debilitating illness, or a history of peanut, ghee or honey allergy, and iii) on other supplementary feeding programs.

During recruitment, baseline information on the child's anthropometry, household food security status, and morbidity status was collected. Anthropometry measurements were taken by trained RAs using standard methods. Weight was measured with an electronic scale (Seca, Hamburg, Germany) to the nearest $0.1 \mathrm{~kg}$, length/height was measured to the nearest $0.1 \mathrm{~cm}$ with a rigid height board, and MUAC was measured with a standard insertion tape to the nearest $0.1 \mathrm{~cm} .{ }^{10}$ Edematous malnutrition (kwashiorkor) was assessed by checking for bilateral pitting edema. The 9-item Household Food Insecurity Access Scale too ${ }^{11}$ was administered to mothers/caregivers to assess household access to food. Morbidity status of the children was established based on a two-week recall by the mothers/caregivers.

\section{Supplementary food products}

SPB was developed by the research team using nutri-survey software package. ${ }^{12}$ Raw materials used for formulation of SPB were sorghum, peanuts, ghee, and honey, locally procured from markets in Karamoja, North Eastern Uganda. Sorghum and peanuts were sun-dried for 5 days to moisture levels below $10 \%$. Sorghum was cleaned by winnowing to remove damaged kernels, non-grain plant materials and any other extraneous matter. Dirt-free sorghum was milled into flour. Peanuts were hand sorted to remove damaged and shriveled kernels and any foreign matter, then roasted for 30 minutes using a charcoal stove before grinding to a semi-coarse paste. Milk from Karamajong Zebu cows was traditionally processed by fermentation for 3 days in pots. Fermented milk was churned by hand in a plastic jerry can early in the morning until butter granules clamped on the top. The butter granules were scooped off, washed to remove the buttermilk, and then matured for 1 week to develop the desired flavor. The ghee was heated using a charcoal stove for 30 minutes to remove impurities. After preparation of raw materials, Nutrisurvey computer software (SEAMEO TROPMED Regional Center for Community Nutrition, University of Indonesia, Jakarta, Indonesia), employing a linear programming technique, was used to generate appropriate component ratios. ${ }^{12}$ The quantity of each raw material depended on composition and the recommended daily allowances for children aged 6-59 months. ${ }^{13}$ The sorghum-peanut blend contained 55.2\% sorghum, 18.6\% peanut, $19.0 \%$ honey, and $7.2 \%$ ghee. Nutritive and antinutrient contents were analyzed to ascertain the nutritional adequacy of SPB (Table 1). ${ }^{1}$

The $\mathrm{CSB}+$ given to children in the comparator group was supplied by the World Food Program (WFP), Uganda. comparison of the nutritive profile of SPB and CSB+ and the recommended levels of nutrients for children with MAM are shown in Table 1. The energy content of SPB and CSB+ was more or less similar, but SPB had higher levels of fat, magnesium, sodium, and manganese. $\mathrm{CSB}+$ had higher levels of protein, iron, calcium, zinc, phosphorous, and potassium.

Table I Nutrient composition of the supplementary foods per $100 \mathrm{~g}$

\begin{tabular}{lllll}
\hline & CSB+ & SPB & \multicolumn{2}{l}{$\begin{array}{l}\text { Recommended levels for } \\
\text { children with MAM }\end{array}$} \\
\cline { 3 - 5 } & & & Food based & $\begin{array}{l}\text { Complement } \\
\text { based }\end{array}$ \\
\hline Energy (kcal/l00 g) & $42 \mathrm{I}$ & 430 & 380 & 380 \\
Protein (\%) & $16.8 \mathrm{I}$ & 14.57 & $24 \mathrm{~g} / \mathrm{l}, 000 \mathrm{kcal}$ & $24 \mathrm{~g} / \mathrm{I}, 000 \mathrm{kcal}$ \\
Fat (\%) & 10.69 & 18.15 & $35 \mathrm{~g} / \mathrm{l}, 000 \mathrm{kcal}$ & $35 \mathrm{~g} / \mathrm{I}, 000 \mathrm{kcal}$ \\
Iron (mg) & 16.67 & 12.08 & 9 & 18 \\
Calcium (mg) & 891.6 & 737.5 & 600 & 840 \\
Magnesium (mg) & 71.83 & 86.83 & 200 & 300 \\
Sodium (mg) & 27.50 & 30.41 & 550 & 550 \\
Manganese (mg) & 0.73 & 2.14 & 1.2 & 1.2 \\
Zinc (mg) & 4.15 & 1.74 & 13 & 20 \\
Phosphorous (mg) & 485 & 380 & 600 & 900 \\
Potassium (mg) & 626.67 & 371.67 & 1,400 & 1,600 \\
\hline Note:Adept
\end{tabular}

Note: Adapted from Amegovu KA, OgwokP, Ochola S, Yiga P, Musalima HJ, Mutenyo E. Formulation of sorghum-peanut blend using linear programming for treatment of moderate acute malnutrition in Uganda. J Food Chem and Nutr. 20।3; I (2):67-77.

Abbreviations: CSB+, corn soy blend plus; SPB, sorghum peanut blend. 


\section{Description of interventions, distribution and utilization of supplementary foods}

At recruitment, participants in the comparator group received a daily ration of $269 \mathrm{~g}$ of $\mathrm{CSB}+$. The rations were distributed on a bi-weekly basis, translating to $3.77 \mathrm{~kg}$ for the 2 weeks. Those in the experimental group received a daily ration of $269 \mathrm{~g}$ per day, translating to $3.77 \mathrm{~kg}$ of SPB for 2 weeks. The CSB+ distributed provided 1,200 kcal per child per day whereas the SPB provided 1,228 kcal per day. These amounts were within the recommended 1,000-1,200 kcal for take home or dry rations. These amounts account for sharing of the food at home amongst other children and adults. Dry rations are intended to supplement the normal diet of the malnourished children and not to replace it. According to the guidelines, all children 6-59 months of age received the same amount of food (Guidelines for Selective Feeding: The Management of Malnutrition in Emergencies, January 2011). With the collaboration of the United Nations Standing Committee on Nutrition and the WHO. ${ }^{15}$

Mothers/caregivers and their children made bi-weekly visits to the health centers and were provided with the food rations for a maximum period of 3 months or 90 days as per the Sphere Standards (2004) recommendations. ${ }^{8}$ The Sphere Standards give guidelines for minimum standards of operations and indicators in emergency situations. During these visits, demonstrations were given on the preparation of porridge from SPB and CSB+ and on the importance of hygiene and the appropriate utilization and storage of the food products. Nutrition education focused on the frequency and amounts of porridge to be given to the children and the general IYCF practices. Anthropometric measurements (weight and height/length) of the children were taken to determine their weight gain and nutritional status. On each visit, caretakers reported on the child's clinical symptoms and adherence to the food supplement.

Children were defined as having recovered when they reached a WHZ $\geq-2$ and had attained $10 \%$ of their admission weight for two consecutive visits. ${ }^{16}$ Children who developed severe acute malnutrition during the study and/or remained malnourished at the end of the 3-month follow-up were considered to have failed the therapy for MAM and were referred to outpatient therapeutic feeding centers or inpatient care, as clinically appropriate in each case, as per the Sphere Standards.

The interventions in the comparator group (CSB+) were similar to those in the experimental group, with the only difference being the type and amount of supplementary food given to the children.

\section{Follow-ups and determination of nutrition outcomes \\ Determination of nutrition outcomes}

The primary outcomes were the MAM recovery rate: percentage of children who attained normal nutrition status ( $\geq-2$ WHZ) within a 3-month period, and the recovery time (the duration within 90 days in which the child recovered from MAM). These indicators are based on the Sphere Standards 2004 recommendations for monitoring and evaluation criteria.

\section{Interviews}

The study questionnaires were developed and face-validated. The questionnaires were subjected to multiple pre-tests during their development and finally pilot-tested and refined for clarity and accuracy.

Similar interviews were conducted with mothers/ caregivers in the two study groups following the same schedule. A baseline interview was conducted with mothers/ caregivers of the children at recruitment in each of the study groups. Subsequent interviews were conducted during the bi-weekly visits to the health facilities to solicit information on the utilization of the supplementary foods, acceptability of the foods by the child, and to establish whether any side effects were observed.

\section{Statistical analysis}

Data were analyzed using the statistical software package SPSS version 17.0 (SPSS Inc., Chicago, IL, USA). Anthropometric indices were based on the WHO 2006 Child Growth Standards, computed using Anthro version 3.1 (World Health Organization, Geneva, Switzerland). ${ }^{16}$ Recovery rate was based on WHZ (wasting). Weight gain (in $\mathrm{g} / \mathrm{kg} / \mathrm{d}$ ), relative to the enrollment weight, was calculated for study groups over the 3-month period (or less if the children recovered earlier). Comparisons of outcomes in the two study groups were assessed using Fisher's exact test for dichotomous variables and Student's $t$-test for continuous variables. The log-rank test was used to compare the duration of therapy in the two study groups. Differences in recovery time in the two study groups were assessed by Kaplan-Meier survival analysis and failure time (AFT) model. The predictors of recovery rate were determined by Cox hazard ratio. The significant value to enter the regression model was 
$P<0.05$ and the hypotheses were tested by a two-tailed test of significance.

\section{Results}

\section{Enrollment process and trial profile for the study participants}

A total of 840 and 760 children were screened in the SPB and $\mathrm{CSB}+$ groups respectively. Of the 234 children who met the selection criteria in SPB and 230 in CSB+, 220 were recruited into each of the study groups (Figure 1).
A total of $198(90.0 \%)$ and $194(88.2 \%)$ of the children in SPB and CSB+ study groups respectively completed the study.

\section{Baseline characteristics of the study population} Sociodemographic characteristics

The majority ( $\geq 95.0 \%)$ of the children enrolled in the study were brought to the health facilities by their mothers. Most of the mothers/caregivers were within the age range

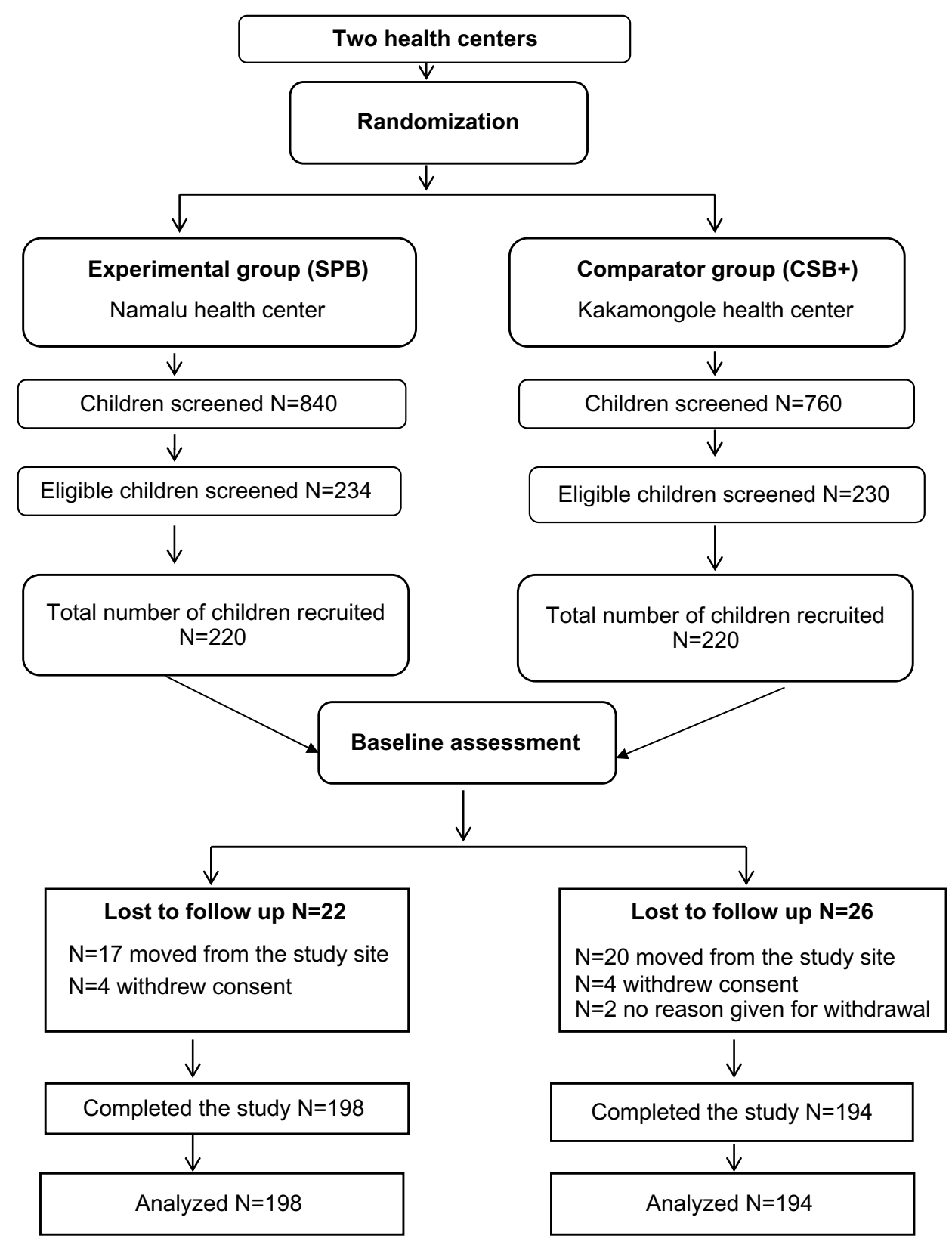

Figure I Schematic presentation of enrollment and completion of study by participants. Abbreviations: CSB+, corn soy blend plus; SPB, sorghum peanut blend. 
of 15-34 years. The education level of caregivers was low, with a high proportion of them having no formal education (Table 2). The mean age of the children in the experimental study group (SPB) was $30.4( \pm 7.3)$ months, and $29.5( \pm 8.3)$ months in the comparator group (CSB+). The majority of the households disposed off feces in private or community latrines and slightly over half of the households treated drinking water. Morbidity prevalence was high among the children, with $65.5 \%$ of the children in the CSB+ and $55.9 \%$ in the SPB groups having had fever in the 2 weeks prior to the study. Only about half of the participants reported acceptable food consumption scores. The study groups were similar in all the sociodemographic aspects with the exception of sex of the child. The CSB+ group had a significantly higher percentage of girls than the SPB group (chi-square test; $P=0.013$ ) (Table 2). Randomization was therefore successful because the groups were similar at baseline.

\section{Baseline anthropometric characteristics of participants}

The significant differences in the anthropometric measurements and indices between the study groups were observed in the means for WHZ and weight-for-age $z$ scores (Table 3). Nonetheless, all the children were moderately malnourished at baseline.

\section{Impact of food supplementation on nutrition outcomes by study groups}

A total of 48 participants were lost to follow up: 26 (11.8\%) from the SPB group and $22(10.1 \%)$ from the CSB+ group (Figure 1).

Table 2 Baseline comparison of the key demographic characteristics, household food security status, and health indicators of the study groups

\begin{tabular}{|c|c|c|c|c|c|}
\hline \multirow[t]{2}{*}{ Characteristics } & \multicolumn{2}{|c|}{$\mathrm{CSB}+(\mathrm{N}=220)$} & \multicolumn{2}{|c|}{ SPB $(\mathbf{N}=220)$} & \multirow{2}{*}{$\begin{array}{l}\text { (Chi-square } \\
\text { P-value) }\end{array}$} \\
\hline & Mean \pm SD & n (\%) & Mean \pm SD & n (\%) & \\
\hline \multicolumn{6}{|l|}{ Respondent's relationship to children } \\
\hline Mother & & $209(95.0)$ & & $210(95.5)$ & 0.8230 \\
\hline Caregiver & & II (5.0) & & $10(4.5)$ & \\
\hline \multicolumn{6}{|l|}{ Education level of respondents } \\
\hline Non-formal education & & $207(94.1)$ & & $204(92.7)$ & 0.7590 \\
\hline Primary & & $12(5.5)$ & & $14(6.3)$ & \\
\hline Secondary & & $0(0.0)$ & & $I(0.5)$ & \\
\hline Tertiary & & $\mathrm{I}(0.5)$ & & $\mathrm{I}(0.5)$ & \\
\hline \multicolumn{6}{|l|}{ Age of respondents (years) } \\
\hline $15-34$ & $30.36 \pm 7.308$ & $164(74.5)$ & $29.5 \pm 8.335$ & I $79(8 \mid .4)$ & 0.1790 \\
\hline $35-44$ & & $44(20.0)$ & & $28(12.7)$ & \\
\hline 45 and above & & $12(5.5)$ & & $12(5.5)$ & \\
\hline \multicolumn{6}{|l|}{ Sex of children } \\
\hline Male & & $96(43.6)$ & & $122(55.5)$ & 0.0130 \\
\hline Female & & $124(56.4)$ & & $98(44.5)$ & \\
\hline Mean age of respondents (months) & $30 \pm 9.1$ & & $3 \mathrm{I} \pm 8.8$ & & \\
\hline \multicolumn{6}{|l|}{ Morbidity based on 2-week recall } \\
\hline Fever & & I44 (65.5) & & II 8 (55.9) & 0.0680 \\
\hline ARI/cough & & II (5.0) & & $15(6.8)$ & \\
\hline Diarrhea & & $20(9.1)$ & & $5(2.3)$ & \\
\hline \multicolumn{6}{|l|}{ Disposal of feces } \\
\hline Private/community latrine & $2.01 \pm 0.746$ & I58 (7I.8) & $1.97 \pm 0.807$ & $152(69.1)$ & 0.5310 \\
\hline Bush/open air & & $62(28.2)$ & & $68(30.1)$ & \\
\hline \multicolumn{6}{|l|}{ Treatment of drinking water } \\
\hline Yes & $0.57 \pm 0.476$ & $123(55.9)$ & $0.43 \pm 0.496$ & $125(56.8)$ & 0.3900 \\
\hline No & & $92(41.8)$ & & $95(43.2)$ & \\
\hline \multicolumn{6}{|l|}{ Children sleeping under ITN } \\
\hline Yes & $0.64 \pm 0.48 I$ & $172(78.2)$ & $0.76 \pm 0.426$ & $169(76.8)$ & 0.7320 \\
\hline No & & $48(21.8)$ & & $51(23.2)$ & \\
\hline \multicolumn{6}{|l|}{ Food consumption scores } \\
\hline Poor consumption & & $46(20.9)$ & & $39(17.7)$ & 0.5720 \\
\hline Borderline consumption & & $75(34.1)$ & & $72(32.7)$ & \\
\hline Acceptable consumption & & $99(45.0)$ & & $109(49.5)$ & \\
\hline
\end{tabular}

Abbreviations: ARI, acute respiratory infections; ITN, insecticide treated nets; CSB+, corn soy blend plus; SPB, sorghum peanut blend; SD, standard deviation. 
Table 3 Baseline anthropometric characteristics of study children

\begin{tabular}{lccl}
\hline $\begin{array}{l}\text { Anthropometric } \\
\text { (Mean } \pm \text { SD) }\end{array}$ & SPB & CSB + & P-value \\
\hline Weight $(\mathrm{kg})$ & $10.1 \pm 2.0$ & $9.8 \pm 1.8$ & 0.135 \\
Height $(\mathrm{cm})$ & $86.3 \pm 9.9$ & $86.3 \pm 8.5$ & 0.992 \\
MUAC $(\mathrm{cm})$ & $12.1 \pm 0.3$ & $12.1 \pm 0.35$ & 0.470 \\
WHZ & $-2.09 \pm 0.12$ & $-2.35 \pm 0.29$ & $<0.00 \mathrm{I}$ \\
Weight-for-age, z score & $-2.27 \pm 0.82$ & $-2.44 \pm 0.89$ & 0.027 \\
Height-for-age, z score & $-1.57 \pm 1.45$ & $-1.5 \mathrm{I} \pm 1.48$ & 0.672 \\
\hline
\end{tabular}

Notes: Values are means $\pm S D$, Weight-for-height $z$ score, $P>0.05$ no significant difference.

Abbreviations: SD, standard deviation; CSB+, corn soy blend plus; SPB, sorghum peanut blend; MUAC, mid-upper arm circumference; WHZ, weight-for-height z score.

\section{MAM recovery rates}

The proportion of children who recovered from MAM was higher in the SPB group (91.4\%) compared to CSB+ (87.1\%), although the difference was not significant (chi-square test; $P$-value 0.193) (Table 4). Non-response rates (children who did not recover from MAM) were $11.8 \%$ and $7.7 \%$ for $\mathrm{CSB}+$ and SPB respectively. The non-response rate reported for children in the CSB+ study group was above the $10 \%$ acceptable level. ${ }^{16}$ No death was recorded during the intervention while morbidity levels were, on the whole, low (Table 4).

\section{MAM recovery time}

The recovery time was significantly different in the two study groups (Figure 2). Children in the $\mathrm{CSB}+$ group recovered faster (median 43 days) whereas the recovery time for those in the SPB was median 57 days (Kaplan-Meier survival analysis).

\section{Predictors of recovery time}

A pooled multivariate AFT analysis of the two study groups showed that the type of supplementary food and baseline age of children were the predictors of recovery rate; $P<0.001$ and
$P=0.021$ respectively. Younger children took a shorter time to reach the target weight compared to older ones, specifically those over 4 years of age, whereas children who consumed $\mathrm{CSB}+$ recovered faster compared to those who consumed SPB (Table 5). Other factors controlled, a unit change in the age of a child measured in months, resulted in a slowing of time taken to reach target weight by a factor of 0.015 . Being on $\mathrm{CSB}+$ accelerated the time it took children to attain target weight by a factor of 12.572 compared to their counterparts on SPB. There was no significant difference observed in recovery rate on the basis of $\operatorname{sex}(P=0.287)$ and the baseline weight-for-height status $(P=0.568)$.

\section{Discussion}

This was the first and the only study so far to compare the efficacy of a locally developed food product using local foods with that of the standard WHO recommended treatment, $\mathrm{CSB}+$ in Uganda. The study aimed to compare the efficacy of SPB and CSB+ in treating MAM. In this randomized trial, there was no significant difference in the recovery rates for children 6-59 months old with MAM who received SPB and those who received CSB+. The acceptable recovery rate to measure the success of a supplementary feeding program is $>75 \%$ based on the Sphere Standards (2004). MAM recovery rates of $>75 \%$ were achieved with both food supplements. The recovery rates for the two food supplements were higher than those reported in many studies in which attaining recovery rates higher than $75 \%$ was a challenge. ${ }^{17,18}$ The relatively high recovery rates achieved with the SPB supplement may be attributed to the fact that the product was comparable to $\mathrm{CSB}+$ in energy content (Table 1). Energy density is vital for the recovery of moderately malnourished children. ${ }^{19}$ Energy is needed for catch-up growth and maintenance. During malnutrition both lean and fat tissue are lost and need to be replaced. ${ }^{13}$

Table 4 Impact of the interventions

\begin{tabular}{|c|c|c|c|c|c|}
\hline \multirow[t]{2}{*}{ Outcome } & \multicolumn{2}{|c|}{ SPB $(\mathbf{N}=198)$} & \multicolumn{2}{|c|}{$\mathrm{CSB}+(\mathrm{N}=194)$} & \multirow{2}{*}{$\begin{array}{l}\text { Chi-square; } t \text {-test } \\
P \text {-value }\end{array}$} \\
\hline & Mean \pm SD & n (\%) & Mean \pm SD & n (\%) & \\
\hline Cured & & 181 (9|.4) & & $169(87.1)$ & 0.193 \\
\hline Not cured & & $17(8.6)$ & & $25(12.9)$ & \\
\hline Fever & & $23(10.5)$ & & $19(8.6)$ & \\
\hline Diarrhea & & $8(3.6)$ & & $8(3.6)$ & \\
\hline Vomiting & & $4(1.8)$ & & I (0.45) & \\
\hline ARI & & $12(5.5)$ & & $10(4.5)$ & \\
\hline Mean $\mathrm{WHZ}$ at discharge & $-0.88 \pm 0.339$ & & $-1.149 \pm 0.43$ & & $<0.00 I^{*}$ \\
\hline Mean HAZ at discharge & $-1.6 \pm 1.45$ & & $-1.6 \pm 1.48$ & & 0.969 \\
\hline
\end{tabular}

Notes: Values are means \pm SD or $n(\%)$; *significant difference.

Abbreviations: WHZ, weight-for-height z score; HAZ, height-for-age z score; SD, standard deviation; CSB+, corn soy blend plus; SPB, sorghum peanut blend; ARI, acute respiratory infections. 


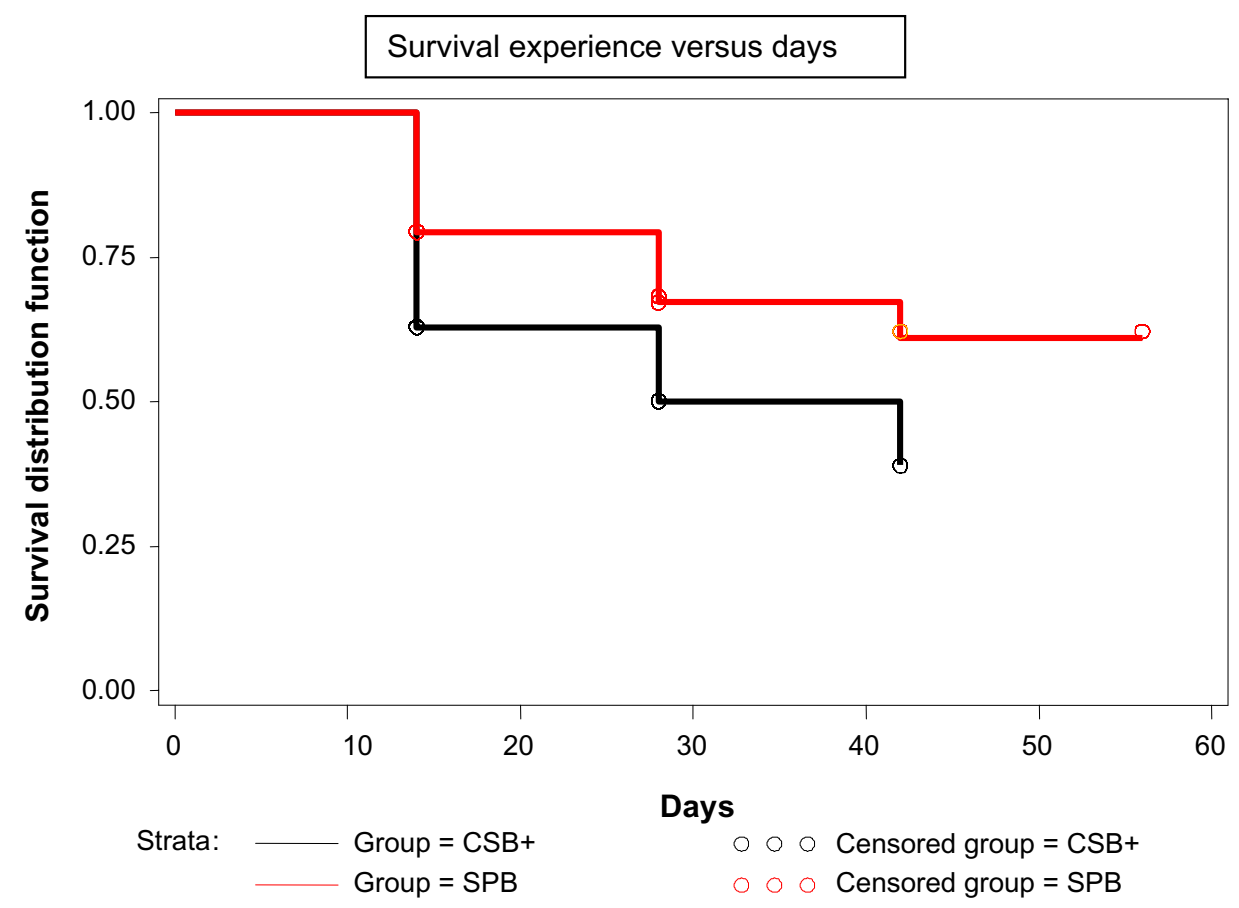

Figure 2 A comparison of survival experiences of children on the two food supplements.

Abbreviations: CSB+, corn soy blend plus; SPB, sorghum peanut blend.

A food supplement with a high energy density directly relates to increased recovery rates. This may have contributed to the high proportion of recovery recorded among children on SPB and CSB+.

Children on $\mathrm{CSB}+$ recovered faster than those on SPB. The nutrient profiles of SPB and $\mathrm{CSB}+$ were not comparable for a number of nutrients. $\mathrm{CSB}+$ had significantly higher levels of protein, $\mathrm{CHO}$, zinc, and potassium whereas SPB had significantly higher levels of fat and anti-nutrients (Amegovu et $\mathrm{al}^{14}$ and Table 1). The nutrient profile of CSB+ was therefore superior to that of SPB. Without fortification, the recommended requirement of some micro nutrients particularly zinc and vitamin A are difficult to meet from a plant-based diet. ${ }^{19,20} \mathrm{CSB}+$ is fortified with micro-nutrients while SPB was formulated locally without any fortification. Zinc is vital for growth and development, and plays a major role in immunity function. Zinc is a growth type II nutrient. ${ }^{13}$ Zinc is related to maintenance requirements, and has direct effects on the primary hormonal system (IGF-I/GH) that controls growth in the postnatal phase. ${ }^{21}$ The zinc content of a diet has a direct relation to the rate of weight gain. ${ }^{13}$ The lower recovery time for children on SPB compared to CSB+ could be partly attributed to the lower zinc level in SPB than recommended for children with MAM. ${ }^{13}$ The inadequacies in

Table 5 Predictors of recovery time

\begin{tabular}{|c|c|c|c|c|c|}
\hline \multicolumn{6}{|l|}{ AFT-model } \\
\hline \multicolumn{4}{|l|}{ Number of subjects $=427$} & \multicolumn{2}{|c|}{$\operatorname{LR} \chi^{2}(4)=263.64$} \\
\hline \multicolumn{4}{|l|}{ Log likelihood =84.964 } & \multicolumn{2}{|c|}{ Prob $>\chi^{2}=0.000$} \\
\hline Characteristic & Time ratio & Coef & SE & $\mathbf{z}$ & $P$-value $>z$ \\
\hline Age at admission & 0.985 & -0.015 & 0.006 & -2.300 & 0.021 \\
\hline \multicolumn{6}{|l|}{ Sex } \\
\hline Female & 1.000 & 0.000 & & & \\
\hline Male & 0.887 & -0.120 & 0.113 & -1.060 & 0.287 \\
\hline \multicolumn{6}{|l|}{ Food item (treatment) } \\
\hline SPB & 1.000 & 0.000 & & & \\
\hline $\mathrm{CSB}+$ & 12.572 & 2.531 & 0.185 & 13.680 & 0.000 \\
\hline Baseline weight-for-height & 0.851 & -0.162 & 0.283 & -0.570 & 0.568 \\
\hline Constant & & -12.659 & 0.964 & -13.140 & 0.000 \\
\hline
\end{tabular}

Abbreviations: AFT, analysis and failure time; LR, log rank; Prob, probability; Coef, coefficient; SE, standard error; SPB, sorghum peanut blend; CSB+, corn soy blend plus. 
the micronutrient levels of SPB could be taken care of through micronutrient supplementation in children. Additionally, the higher level of anti-nutrients in SPB probably interfered with the metabolism of nutrients. ${ }^{14}$

Despite the fact that SPB was made from culturally known and acceptable foods, $\mathrm{CSB}+$ has been used for a long time as the supplement for treating MAM and is thus regarded as a "medicine" with well-known feeding protocols in the study area. CSB+ is organoleptically acceptable in many settings. ${ }^{18}$ Supplementary foods which are similar in appearance to staple foods are usually regarded as mere foods rather than a treatment, thus encouraging sharing, particularly in food insecure areas. ${ }^{18}$ It is probable that there was more sharing of SPB rations than for CSB+ and this may be one explanation why children in the experimental group took longer to reach target weights.

Children's age was found to be a predictor of recovery rate, with younger children recovering faster than older children. Growth rates are directly related to age, with young children growing at faster rates. ${ }^{16}$ Breast milk provides almost three quarters of recommended energy from fats. ${ }^{22}$ Some of the younger children were still breast feeding, thus the combination of breast milk and food supplements may have partly contributed to the accelerated growth in the younger children.

The findings of this study demonstrate that it is possible to achieve the recommended recovery rates as per the Sphere Standards 2004 with appropriate formulations using local food materials. One challenge in using formulations from local food materials is the seasonal availability of such foods. This would interfere with the sustainability of this approach for the treatment of MAM. Karamoja district, where the study was conducted, is a predominantly dry area with unimodal patterns of rainfall and this is likely to cause a challenge in the sustainability of the use of the food product.

A limitation in the design of this study was that health centers (clusters) rather than children were randomized to the study groups. This was necessary to minimize crosscontamination of the intervention by sharing of the food products across the food groups since the two food products were not similar in color and taste. More health centers could have been sampled per study group but the logistics of conducting the study in many facilities in terms of coordination and quality control would have been too complex. Furthermore, having more health centers would have meant additional costs. It is acknowledged that randomization of the health facilities could have implications on the interpretation of the results, which may be confounded by the practices of the health care providers at the centers. This was minimized by the fact that the research team was trained to provide standard nutrition and health education to the study participants in the two study groups. Another limitation of this randomized study was that at baseline children in the CSB+ group were significantly more undernourished than those in the SPB in terms of wasting and being underweight. The authors believe that this did not affect the outcomes; the findings indicated that wasting at baseline did not significantly affect the recovery time. This study did not investigate the compliance to the product by children apart from self-reports by mothers/caregivers, which indicated that children liked both products. Sharing of the product was not investigated either, but a protection ration (additional food over and above that required by the child) was given to minimize this practice. The study did not test the shelf life of the developed SPB product. The shelf life of the product is critical if this product is to be used in future as a supplementary food for rehabilitating children with MAM.

\section{Conclusion}

The local food supplement SPB can be used in the treatment of MAM in places where sorghum, peanut, honey, and ghee are readily available and commonly eaten. The outcomes of this study have the potential for development of a cost-effective and sustainable approach in the treatment of MAM in the site of study and other regions with similar circumstances. Moreover, SPB can easily be prepared by the community because it uses the same food preparation methods that the people are used to and that have been used traditionally. Perhaps fortification of the product with zinc and other micronutrients to meet the recommended requirements is a possibility, but this may have cost implications. A cheaper alternative may be micronutrient supplementation in children using products such as sprinkles. Refinement of the product to reduce the anti-nutrient levels using food processing methods such as fermentation will need to be tested in future studies. Future studies should also test issues such as the product's shelf life, and community perceptions of the product as treatment for MAM, as well as its sustainability and cost-effectiveness. Nonetheless, seasonal availability of these foods may have implications for the maintenance of MAM treatment using these foods.

\section{Acknowledgments}

This work is indebted to the mothers and their young children who willingly participated in the study. The research team is grateful to the RAs, village health teams, and health center 
focal persons for their participation during enrollment and follow-up. We are also grateful to WFP Uganda, Andre Food Consult, and District Health office, Nakapiripirit District.

\section{Disclosure}

The authors had no conflicts of interest to declare.

\section{References}

1. Black RE, Allen LH, Bhutta ZA, et al. Maternal and child under nutrition: global and regional exposures and health consequences. Lancet. 2008;371(9608):243-260.

2. Fishman SCL, de Onis M, Blossner M, Mullany L, Black RE. Malnutrition and the global burden of disease: underweight. Cambridge, MA: World Health Organization/Harvard University Press; 2003.

3. Chang CY, Trehan I, Wang RJ, Thakwalakwa C, et al. Children successfully treated for moderate acute malnutrition remain at risk for malnutrition and death in the subsequent year after recovery. $J$ Nutr. 2013;143(2):215-220.

4. De Pee S, Bloem MW. Current and potential role of specially formulated foods and food supplements for preventing malnutrition among 6- to 23-month old children and for treating moderate malnutrition among 6- to 59-month-old children. Food Nutr Bull. 2009;30(Suppl 3): S434-S463.

5. Acham H, Kikafunda JK, Tylleskar T, Malde MK. Nutritional and health status of primary school children in rural Uganda. African Journal of Food, Agriculture, Nutrition and Development. 2012;12(2): $5862-5880$

6. Uganda Bureau of Statistics, Kampala, Uganda. Uganda Demographic and Health Survey. Measure DHS project, ICF International, Calverton, Maryland, USA; 2011. Available from: http://www.ubos.org/onlinefiles/ uploads/ubos/UDHS/UDHS2011.pdf. Accessed June 19, 2014.

7. Ashworth A, Ferguson E. Dietary counseling in the management of moderate malnourishment in children. Food Nutr Bull. 2009; 30(Suppl 3):S405-S433.

8. The Sphere Project. Standards in Food Security, Nutrition and Food Aid. Oxford: Oxfam Publishing; 2004.

9. Lwanga SK, Lemeshow S. Sample size determination in a health study. World Health Organization. 1991;1-3.

10. Cogill B. Anthropometric Indicators Measurement Guide. Washington, DC: Food and Nutrition Technical Assistance Project, Academy for Educational Development; 2003. Available from: http://www.ergo-eg. com/uploads/books/anthro_1.pdf. Accessed June 19, 2014.

11. Knueppel D, Demment M, Kaiser L. Validation of the Household Food Insecurity Access Scale in rural Tanzania. Public Health Nutr. 2010;13(3):360-367.
12. Erhardt J. Nutrisurvey software version 2007. [Updated 2012/04/04; cited 2007/08/08]. Available from: http://www.nutrisurvey.de. Accessed July 20, 2014.

13. Golden M. Proposed nutrient requirements of moderately malnourished populations of children. Food Nutr Bull. 2009;30(3):S267-S342.

14. Amegovu KA, Ogwok P, Ochola S, Yiga P, Musalima HJ, Mutenyo E. Formulation of sorghum-peanut blend using linear programming for treatment of moderate acute malnutrition in Uganda. J Food Chem and Nutr. 2013;1(2):67-77.

15. The UN Refugee Agency. UNHCR: Guidelines for selective feeding; the management of malnutrition in emergencies, Geneva, Switzerland. Geneva: The UN Refugee Agency; 2011. Available from: http://www. unhcr.org/4b7421fd20.pdf. Accessed July 21, 2014.

16. WHO (World Health Organization). Child Growth Standards: Methods and Development. Geneva, Switzerland. 2006. Available from: http:// www.who.int/childgrowth/standards/technical_report/en/. Accessed June 19, 2014.

17. Matilsky DK, Maleta K, Castleman T, Manary MJ. Supplementary feeding with fortified spreads results in higher recovery rates than with a corn/soy blend in moderately wasted children. $J$ Nutr. 2009;139:773-778.

18. LaGron LN, Trehan I, Meuli GJ, et al. A novel fortified blended flour, corn-soy blend "plus-plus," is not inferior to lipid-based ready-to-use supplementary foods for the treatment of moderate acute malnutrition in Malawian children. Am J Clin Nutr. 2012;95(1):212-219.

19. Michaelsen KF, Hoppe C, Roos N, et al. Choice of foods and ingredients for moderately malnourished children 6 months to 5 years of age. Food Nutr Bull. 2009;30(Suppl 3):S343-S404.

20. Dop MC, Benbouzid D. Regional features of complementary feeding in Africa and the Middle East. In: Dop MC, Benbouzid D, Trèche S, de Benoist B, Verster A, Delpeuch F, editors. Complementary Feeding of Young Children in Africa and the Middle-East. Geneva: World Health Organization (WHO/NHD/99.3 edt. WHO/AFRO/NUT/99.4); 1999:43-58.

21. Rivera JA, Hotz C, Gonzalez-Cossio T, Neufeld L, Garcia-Guerra A. The effect of micronutrient deficiencies on child growth: a review of results from community-based supplementation trials. $J$ Nutr. 2003;133(11 Suppl 2): 4010S-4020S

22. FAO/WHO. Fats and Fatty Acids requirements in Human Nutrition. Interim Summary of Conclusions and Dietary Recommendations on Total Fat and Fatty Acids of a Joint FAO/WHO Expert Consultation. Geneva: World Health Organization; 2008. Available from: http://www. fao.org/ag/agn/nutrition/docs/Fats\%20and\%20Fatty\%20Acids\%20 Summary.pdf. Accessed June 19, 2014.
Nutrition and Dietary Supplements

\section{Publish your work in this journal}

Nutrition and Dietary Supplements is an international, peer-reviewed, open access journal focusing on research into nutritional requirements in health and disease, impact on metabolism and the identification and optimal use of dietary strategies and supplements necessary for normal growth and development. The journal welcomes papers covering
Dovepress

original research, basic science, clinical \& epidemiological studies, reviews and evaluations, guidelines, expert opinion and commentary, case reports and extended reports. The manuscript management system is completely online and includes a very quick and fair peer-review system, which is all easy to use. 